\title{
CAS Honors International Cooperators
}

The Chinese Academy of Sciences (CAS) honored three prestigious scientists, respectively from the Netherlands, the United States and Germany. in recognition of their contributions to the Academy.

At a small-scale ceremony held on January 16 during the session of the Academy's annual conference. CAS President BAI Chunli conferred the medals of the CAS Award for International Cooperation to the awardees: Dutch astronomer Richard Gordon Strom. American physicist Sokrates Theodore Pantelides, and German environmental scientist Ewald Schnug.

Prof. Strom is the only international expert participating in the construction of FAST, the Fivehundred-meter Aperture Spherical Radio Telescope located in southwestern China. With his threedecade-long cooperation with the Academy. Prof. Strom has greatly contributed to the pre-research and establishment of the telescope. and played an instrumental role in connecting the Academy to the global radio astronomy community.

A pioneer expert in semiconductor physics from Vanderbilt University of the LSA. Prof. Pantelides has spent two decades with CAS in developing new low dimensional materials. A researcher dedicated to soil

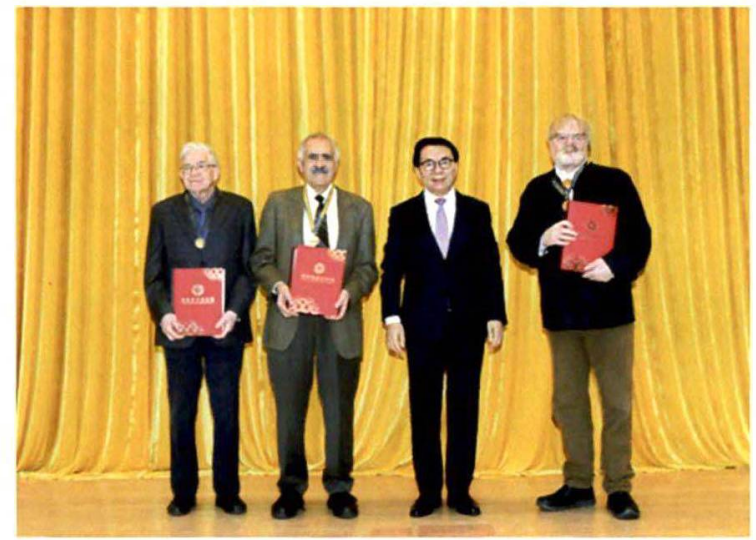

CAS President BAI Chunli (second from right) confers medals to the awardees. (Credit: CAS)

and environmental science. Prof. Schnug has worked with the Academy for over 20 years, improving its technologies for fertilizer processing.

Since 2007, the Academy has awarded 37 foreign scientists for their contributions. Among them, 25 were later awarded China's National Award for International Cooperation in Science and Technology, and 23 the Friendship Award of the nation, the highest honor available for international friends.

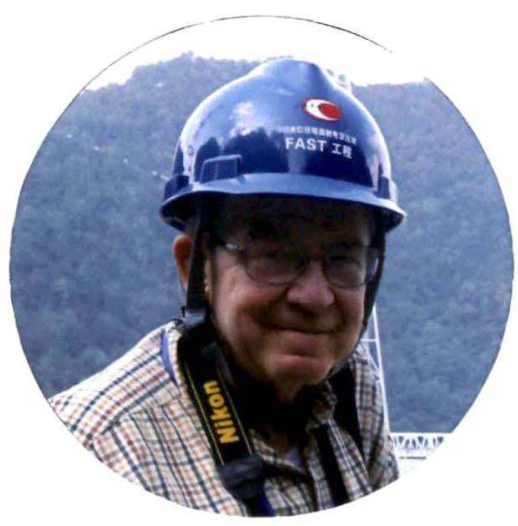

Dutch astronomer Richard Gordon Strom (Credit: CAS)

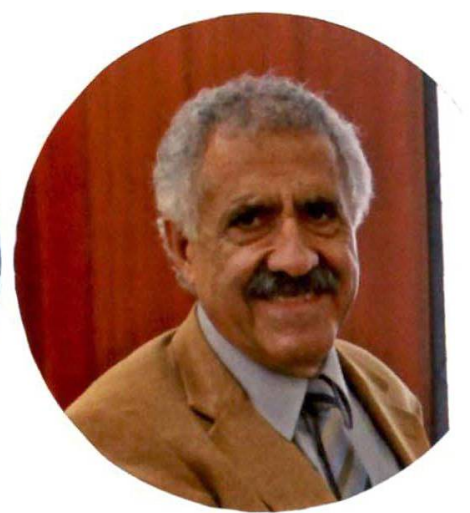

American physicist Sokrates Theodore Pantelides (Credit: CAS)

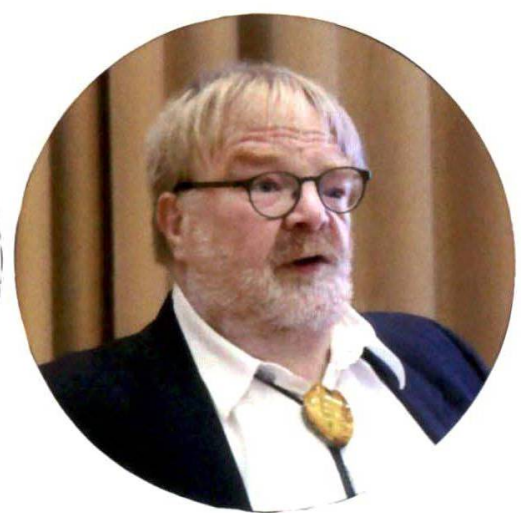

German environmental scientist Ewald Schnug (Credit: CAS) 